\title{
UTILIZAREA MIJLOACELOR MULTIMEDIA ÎN MISIUNEA BISERICII - SITE-UL PAROHIAL -
}

\author{
Viorel Vlăducu*
}

\begin{abstract}
Today, the Church is called to use all means of communication in the work in preaching the word of God. The Internet has arrived in this technological era at a level that no one fore see a few years ago. The parish site is a virtual space where surfers - believers from all over the world-have contact with the life of the community.It is a modern way of communication that more parishes use today. A better knowledge and depth of content and technical details will lead to a better quality of the website.
\end{abstract}

Keywords: Internet, communication, website, parish, mission

\section{Preliminarii}

În istoria lumii, comunicarea a marcat întotdeauna relațiile interumane. Astăzi însă, tehnologiile moderne de comunicare „,provoacă schimbări spectaculoase în peisajul culturilor

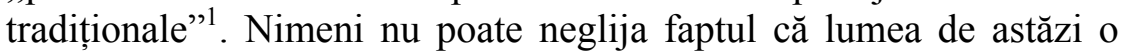
înţelegem ,,prin intermediul imaginilor"’2.

Epoca tehnologică are implicaţii şi în viaţa religioasă şi morală a omului $^{3}$ şi de multe ori prin ,mijloacele de comunicaţie”

* PhD Candidate at Faculty of Orthodox Theology, "1 Decembrie 1918" University of Alba Iulia.

${ }^{1}$ Pr. Nicolae Dascălu, Comunicare pentru comuniune, Iaşi, Ed. Trinitas, 2000, p. 141.

${ }^{2}$ Ierom.dr.Teofan Mada, Evanghelia în versiunea Hollywood, Cluj Napoca, Ed. Vremi, 2010, p. 15.

3 Chris Arthur, The Globalization of Communications. Some religious implications, Geneva, WCC Publications, 1998, p. 2. 
urmărindu-se chiar o accentuare a imoralităţii şi a antireligiosului, mai ales în rândul tinerilor ${ }^{4}$.

Într-o societate normală, ,educație oferă şi familia şi Biserica şi părintele şi preotul şi prietenul şi vecinul, precum şi radioul, teatrul, televizorul, cartea...parlamentul....". care a ajuns astăzi ceva atât de uzual şi de dezvoltat, încât poate nimeni nu putea prevedea acest fapt acum 25-30 de ani. Numeroase instituții, asociații sau comunității au site de prezentare. Epoca WWW influențează majoritatea domenilor de activitate.

În lumea de azi, a folosi tehnica în misiunea Biserici este un lucru absolut necesar. Slujitorul Bisericii este dator să folosească toate mijloacele disponibile în misiunea de propovăduire a cuvântului lui Dumnezeu.

În cele ce urmează vom surprinde câteva aspecte esenţiale legate de realizarea şi importanța unui site parohial.

Chiar dacă tehnica evoluează foarte rapid şi adaptarea la cerințele vremii este anevoioasă şi costisitoare, utilitatea unui site parohial este foarte mare.

\section{Studierea unor site-uri model}

Un prim pas în alcătuirea unui site parohial este cercetarea (vizualizarea detaliată) a unui număr cât mai mare de site-uri parohiale dar şi a altor site-uri religioase. Există deja portaluri (ex: www.parohiiortodoxe.ro) ce oferă legături către numeroase site-uri parohiale ortodoxe româneşti.

Materialul necesar realizării site-ului cuprinde informații despre parohie şi fotografii reprezentative. Pagina principală conține legături către celelalte pagini ale site-ului. De obicei, aceste legături sunt grupate într-o secțiune numită meniu.

\footnotetext{
${ }^{4}$ Hristodoulos, Arhiepiscop al Atenei şi Primat al Greciei, Misiunea socială a Bisericii, trad. din lb. greacă de Arhi. Mihail Filimon, Pr. Petru Sidoreac, Protos. Dosoftei Scheul, Iaşi, Ed. Trinitas, 2000, p. 53.
}

${ }^{5}$ Ibidem,pp. 51-52. 
Pagina principală se comportă ca o intersecție cu multe indicatoare, precum cuprinsul unei cărți. Paginile site-ului sunt grupate pe categorii, precum capitolele cărții. Astfel, puteți considera un site ca o carte ilustrată. A proiecta un site este la fel cum ați edita o broşură despre parohia dumneavoastră.

Site-ul parohial nu este o alternativă la metodele tradiționale de catehizare, ci doar le îmbunătățeşte, fiind un important sprijin auxiliar.

Un site parohial bun reflectă o activitate pastorală complexă. Prin site, credincioşii pot afla amănunte despre parohia de care aparțin şi pot afla în timp real de activităţile ce se desfăşoară în cadrul parohiei.

La realizarea site-ului trebuie implicați cât mai mulți enoriaşi. Se poate oferi spațiu în cadrul site-ului unor articole sau materiale frumoase venite de la enoriaşi.

Pagina de Internet a parohiei trebuie îmbunătățiă permanent, întrucât mereu se găseşte ceva de adăugat sau modificat. Site-ul parohiei este o moştenire ce o veți lăsa generațiilor viitoare, care la rândul lor îl vor îmbunătăți.

Crearea unui site cu un bogat conținut informațional este un proces de durată.

\section{Conținutul site-ului parohial}

Furnizăm în continuare o posibilă soluție de organizare a unui site parohial, sugerând câteva categorii principale.

Programul slujbelor. La majoritatea parohiilor, duminica, la finalul Sfintei Liturghii preotul anunță programul slujbelor săptămânii ce urmează. Postarea acestui program pe site este foarte utilă. Se recomandă postarea unui program, actualizat pentru fiecare săptămână.

Pangarul bisericii/Magazin bisericesc. Prezentarea obiectelor de cult şi a cărților disponibile.

Biblioteca parohială. Creați o bază de date electronică cu cărțile disponibile şi postați-o pe site. Prezentați procedeul de 
împrumut precum şi detaliile persoanei de contact. Se poate organiza şi o bibliotecă multimedia conținând CD-uri şi DVD-uri cu materiale duhovniceşti. Se poate face un apel pentru îmbogățirea fondului de carte al bibliotecii dar şi al fondului media.

Această rubrică poate fi completată cu alte modalității de a dona precum şi cu sfaturi duhovniceşti despre importanţa milosteniei. Tot aici se prezintă şi destinaţia donaţiilor (pictură, restaurare, sonorizarea bisericii, achiziționarea unor obiecte de cult, servicii sociale, etc.). Cunoaşterea destinației fondurilor obținute din donații constituie o motivație pentru credincioși de a oferi ajutor bisericii.

$2 \%$ te ajută. Informația despre $2 \%$ trebuie prezentată separat, Următorul text poate fi postat la această rubrică: „Dacă vreți să contribuiți la finalizarea lucrărilor de la biserica Parohiei...., completați formularul 230, pe care îl puteți găsi la pangarul bisericii sau descărca de aici:(includeți o fotografie a formularului cu legătură către fişierul în format pdf). Completați doar datele dumnevoastră personale, apoi depuneți formularul la pangarul bisericii.

Preoți slujitori. Se afișează datele de contact ale preoților slujitori (telefon, e-mail, etc.). Menționați aici şi pe acei preoți slujitori ai bisericii trecuți la Domnul care au rămas în memoria credincioşilor: „în perioada...parohia noastră a fost păstorită de vrednicul de pomenire, părintele....".

Pelerinaje. Parohia poate organiza pelerinaje sau se poate implica în pelerinajele organizate de alte parohii sau organizații. De asemenea, se pot posta pelerinaje organizate de centrele eparhiale apropiate parohiei. Exemple: Centrul de Pelerinaj Sfântul Apostol Pavel al Patriarhiei Române (www.pelerinaj.ro), Centrul de Pelerinaj Sfantul Nicodim al Mitropoliei Olteniei (www.pelerinaje.ro), etc. La această secțiune se pot adăuga informații despre pelerinajele la manăstirile din apropiere organizate cu ocazia hramurilor acestora.

Sfântul ocrotitor. Postați informații despre sfântul ocrotitor al parohiei: viața, minuni, acatistul, cântari, icoane, imagini cu sfintele moaşte. Exemplu: www.sfantulnectarie.ro. 
Activități filantropice. Să nu-i uităm pe enoriaşii săraci! Prezentați eventualele activități filantropice şi posibilitățile de participare la ele. Expuneți metode de identificare a adevăratelor cazuri sociale din parohie.

Activități cu tinerii. Consultați proiectul lansat de Patriarhia Română „Hristos impartasit copiilor” (www.hristosimpartasitcopiilor.com).

Parteneriate. Prezentaţi eventualele parteneriate cu şcoli, grădinițe, universităţi, muzee, cămine pentru vârsnici, etc.

Corul bisericii/Grupul psaltic. Pentru prezentarea corului se pot posta: membrii corului, dirijorul, fotografii, cântări în format audio sau video, detalii contact, disponibilitatea de a cânta la slujba sfintei cununii. Exemple: Corul Kinonia al Episcopiei Severinului şi Srehaiei, Corul de muzică psaltică Byzantion (www.byzantion.ro), etc. Vizualizați ca model paginile de Internet ale câtorva grupuri psaltice cunoscute.

Istoric. Istoricul parohiei cuprinde într-o anumită măsură şi aspecte ale istoricului cetății, comunității, tradiților locale. Este încă o dovadă că Biserica contribuie la păstrarea tradițiilor româneşti.

Sigle. Este o datorie în a include pe site sigla eparhiei de care aparține parohia. Se pot, de asemenea include sigle ale posturilor de radio ortodoxe ce pot fi receptate în zonă, ale agenției de ştiri Basilica, ale Ziarului Lumina, etc.

\section{AGEMTHA DESTTRB BASLICA}
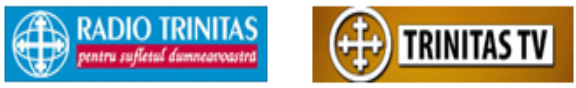

$\overline{\text { Ziarul Lumina }}$

Legături Web. Includeți legături către site-urile parohiilor învecinate, site-urile menționate la secțiunea sigle dar şi către alte site-uri ce recomandă site-ul dumneavoastră. 


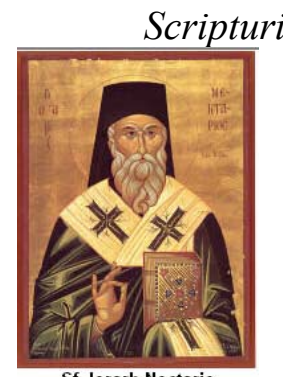

Icoana zilei este un script oferit de site-ul www.sinaxar.ro. A fost deja preluat de peste 200 de site-uri. Inclus pe site, scriptul afişează icoana unuia sau mai multor sfinți din ziua respectivă. Are 6 variante. Mai multe detalii se pot obține de pe www.sinaxar.ro.

Sf. lerarh Nectarie

din Eghina,

noul făcător de minuni

Alături de scriptul icoana zilei se poate include scriptul calendar ortodox oferit gratuit în trei modele: modelul 1 oferit de www.credo.ro, modelul 2 oferit de www.calendar-ortodox.ro, modelul 3 oferit de www.e-mistic.org.

\begin{tabular}{c}
\hline Miercuri, 9 noiembrie \\
SFINTII ZILEI \\
- Sf. Ierarh Nectarie din \\
Eghina, noul făcător de \\
minuni \\
- Sf. Mucenici Onisifor si \\
Porfirie \\
- Sf. Cuvioasa Matroana \\
- Sf. Cuvioasa Teoctista \\
Lesvianca \\
- Sf. Cuvios Simeon Metafrast \\
- Sf. Femei Eustolia si Sopatra \\
- Sf. Mucenic Antonie \\
- Sf. Cristofor si Mavra \\
- Sf. Ioan Colovul \\
- Sf. Cuvios Eladie \\
- Sf. Mucenici Narsi si \\
Artemon \\
- Sf. Cuviosi si de Dumnezeu \\
purtători Părinti Evtimie si \\
Neofit, ctitorii mănăstirii \\
Dohiarului \\
\hline Click pe sfinti pentru Sinaxarul \\
zilei sau click aici pentru \\
sinaxanul in fomataudio mo3 \\
\hline
\end{tabular}

Modelul 2 este cel mai popular fiind preluat până în prezent de peste 1100 de siteuri cu specific religios şi nu numai. Inclus pe site scriptul afişază un tabel ce conține lista completă cu numele sfinților din ziua respectivă. Datele sunt preluate din Minei, deci lista este mult mai amplă decât în calendarul ortodox de perete. Scriptul oferă posibilitatea stabilirii culorilor şi a dimensiunii tabelului precum şi o legătură către o pagină cu viețile sfinților din ziua respectivă. La baza tabelului este inclusă o legătură către sinaxarul audio al zilei respective. Rubrica audio sinaxar este realizată de părintele arhidiacon Adrian Mazilița şi este găzduită de site-ul www.sinaxar.ro. 
Media. Cuprinde secțiuninile: video, audio şi foto. Filmulețele video sunt de impact. Se pot filma fragmente din unele slujbe importante sau activități ale parohiei şi apoi pot fi postate pe site. Se pot posta diverse înregistrări audio: predici, interviuri, cântări, etc. De asemeena, se postează fotografii grupate în diverse categorii reprezentative pentru activitatea parohiei.

Se includ pe site şi materiale audio-video sau foto vechi. O filmare a sfințirii bisericii de acum 30 de ani, fotografii vechi ale bisericii sau diverse înregistrări audio sunt foarte valoroase indiferent de calitatea imaginii sau a sunetului.

Localizare.

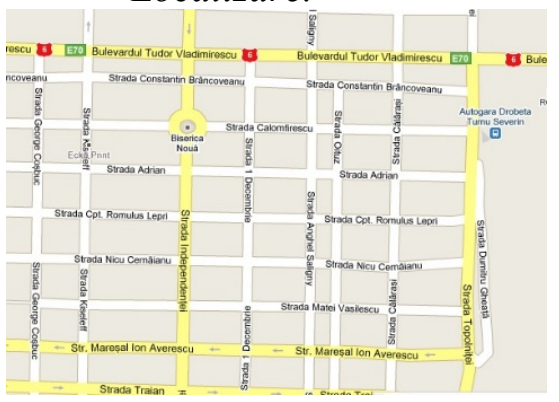

Accesați utilitarul Google maps de la pagina http://maps.Google.com. Localizați zona în care vă aflați şi captați o imagine ca în exemplul alăturat.

Patrimoniu. Dacă biserica parohiei a fost declarată biserică de patrimoniu (monument istoric) şi deține diverse aspecte de interes turistic, prezentați-le pe site. Câți vizitatori nu atrage albastrul de Voroneț! O pictură de-a lui Tătărăscu sau Grigorescu, o icoană sau arhitectură celebră pot aduce numeroşi turişti la biserica dumneavoastră. A pune în valoare obiectele de patrimoniu deținute de o parohie nu este uşor. Pentru realizarea unei evidențe, puteți apela la ajutorul istoricilor şi muzeografilor din zonă. O parohie ce deține o colecție de carte veche, icoane sau obiecte de cult poate organiza un frumos muzeu parohial.

Ştiri. În general, ştirile se postează pe prima pagină a site-ului pe una sau două coloane. Este secțiunea care se actualizează cel mai des. Rubrica poate cuprinde: diverse anunțuri, evenimente, ştiri importante religioase. 
Evenimente. Se prezintă principalele evenimente din activitatea parohiei. Rubrica este de fapt o arhivă a celor mai importante ştiri. Se includ numeroase fotografii sugestive.

Newsletter. Ce este un newsletter? O publicație electronică de obicei periodică, ce cuprinde diverse informatii dintr-un anumit domeniu. Un newsletter este similar unei publicatii tipărite distribuite prin poştă. Prin acest utilitar se pot trimite abonaților care au consimțit să primească acest newsletter mesaje conținând: articole ale secțiunii de ştiri, activităti, programul slujbelor săptămânii, etc.

Ctitorul. Se prezintă biografia ctitorului bisericii şi contribuția pe care a avut-o acesta la ridicarea sfântului lăcaş.

Program pastoral. Se prezintă programul disponibilității preotului pentru acordarea sfintei spovedanii şi a altor servicii religioase, programul catehezelor, etc. Tot aici se poate adăuga şi programul tradiționalelor vizite la domiciliu cu ocazia Crăciunului şi a Bobotezei. Enoriaşii pot astfel cunoaşte ziua şi orele când se va efectua vizita preotului. Afişele lipite la avizierele blocurilor dar şi postate pe site sunt un eficient mijloc de informare.

Revista/Foaia parohială. Se prezintă detaliat revista parohială, periodicitatea sa, posibilitatea de achiziție. Specificați modalitatea trimiterii unui articol prin Internet (mail sau un formular special). Se postează o arhivă cu toate aparițile revistei parohiale în format electronic..

Tur virtual/Imagini panoramice. Se realizează un tur virtual. Pentru a vă face o părere despre eficiența unui tur virtual vă propun vizualizarea următorului exemplu:

www.patrimoniuepiscopiaseverinului.ro (secțiunea muzeu virtual).

Arondare. Exemplu: „Parohia noastră cuprinde credincioşii ortodocşi ce locuiesc în următoarele zone: str. Calomfirescu, str. Şincari nr. 10 -80, cartierul ...." 


\section{Aspecte tehnice}

Atunci când creați un site web trebuie să faceți trei alegeri esențiale: cine va fi gazda (serverul), cine realizează site-ul (webmasterul) şi care va fi numele site-ului. Mulți acordă puțină atenție acestor alegeri, totuşi o casă bună este construită pe temelii bune şi aceste aspecte au o importanţă majoră.

Alegerea gazdei. Gazduirea site-ului se face pe un calculator numit server web. Trebuie să alegeți un furnizor ce oferă servicii de găzduire Web. Nu subestimați această decizie! Aceasta este o direcție în care nu trebuie să faceți economii. O gazdă bună ar trebui sa vă garanteze funcționalitatea neîntreruptă a site-ului şi o viteză de încărcare a site-ului mulțumitoare. $\mathrm{O}$ gazdă rapidă, fiabilă cu severe moderne este şi o gazdă mai scumpă. Modul cel mai bun pentru a avea un site care să se încarce fulgerător este să plătiţi pentru un asemenea serviciu. O recomandare ar fi să alegeți un furnizor din țară, cu care să puteți avea contact uşor. Puteți alege unul din furnizorii care găzduieşte unul din site-urile care vă place cum funcționează. Aflați cine găzduiește un site accesând www.domaintools.com.

Alegerea Webmasterului. Wemasterul este specialistul în domeniu, care, pe baza materialelor primite, realizează site-ul. De alegerea webmasterului depinde cât de frumos va arăta site-ul dumneavoastră şi cât de bine va funcționa. Webmasterul este asemenea unui inginer care însă nu construieşte o biserică, ci un site după cerințele dumneavoastră.

Numele site-ului. Un prim pas în alegerea numelui este consultarea mai multor nume ale site-urilor parohiale existente. Mai multe exemple gasiți pe www.parohiiortodoxe.ro. Când alegeți un nume trebuie inițial să verificați dacă numele respectiv nu a fost ocupat, adică există deja un site cu acel nume. Testaţi dacă numele este disponibil la www.domaintools.com. Numele unui site trebuie să reflecte cât mai bine conținutul site-ului, să fie cât mai scurt şi să fie uşor de reținut. 
Un nume potrivit se obține prin unirea cuvântului parohie cu numele satului www.parohianumelesatului.ro sau www.parohianumelesatului.ro. $\mathrm{Cu}$ cât un nume de site este mai uşor de memorat $\mathrm{cu}$ atât numărul de vizitatori poate fi mai mare. Mai trebuie să ştiți următoarele: fiecare site face parte dintr-o anumită categorie determinată de ultimele caractere: .ro (site-uri româneşti), .org(siteuri ale organizaților), .eu(site-uri europene), .info, .com, etc.; DNS (Sistemul de Nume de Domeniu) este cartea de telefoane a internetului. De fiecare dată când accesaţi de exemplu site-ul www.parohiaorsova.ro DNS este întrebat: pe ce server se găseşte site-ul www. parohiaorsova.ro? DNS răspunde: serverul cu adresa 188.214.17.32. Dacă DNS nu ar exista atunci am fi nevoiți să memorăm o mulțime de cifre în loc de un nume uşor de reținut. Serviciul DNS vă este de obicei oferit de către furnizorul serviciilor de găzduire.

Numele ales îl comunicaţi webmasterului care se va ocupa de înregistrarea acestuia. Nu uitați că odată ales acesta nu se mai poate schimba (,Marfa vândută nu se schimbă"). Înregistarea unui domeniu de tipul .ro se face la pagina www.rotld.ro, prețul fiind de 51,26 USD + TVA (24\%). Dacă înregistrați domeniul la unul din partenerii Rotld s-ar putea să găsiţi un preț puțin mai mic. După înregistare primiți o factură pentru plata efectuată; aceasta constituie garanția deținerii domeniului (numelui site-ului).

\section{Promovarea site-ului}

Promovarea verbală şi prin presa locală. Profitați de orice dialog cu credincioşii pentru a anunța apariția site-ului. Vorbiți-le despre conţinutul şi utilitatea lui. Anunţaţi la finalul Sfintei Liturghii lansarea site-ulului. Scrieți în presa locală articole despre existența site-ului.

Promovarea prin alte site-uri. Contactați prin mail administrartorii altor site-uri parohiale, ale site-ului centrului eparhial de care apartineți sau ale altor site-uri ortodoxe şi solicitați includerea unei legături către site-ul dumneavoastră. Adăugați la 
rubrica dumneavoastră de legături site-urile recomandate. Puteți solicita includerea unei legături şi administratorilor site-urilor care nu au specific religios, dar care ar putea manifesta interes: site-ul primăriei sau al oraşului, site-uri care promoveză valorile culturale şi spirituale, site-uri ce prezintă obiectivele turistice sau diverse asociații. Site-ul unei parohii cu o biserică monument istoric de patrimoniu are şanse mari să fie recomandat de numeroase site-uri culturale şi turistice.

Promovarea prin cataloagele Web. Un calalog web sau director web este un site ce conține legături către numeroase site-uri. Inscrieți site-ul în cât mai multe astfel de directoare web. Majoritatea oferă înscriere gratuită. Pentru includerea unei legături către site-ul dumneavoastră accesați rubrica „Adauga site” sau „Adauga link” de pe pagina principală. Se deschide un formular ce conține de obicei următoarele rubrici: Titlul site-ului, Scurt comentariu, Email de contact, Adresa site-ului şi Categoria.

Promovarea prin motoarele de căutare. Este o sarcină destinată exclusiv webmasterului. Cel mai cunoscut şi folosit motor de căutare este Google. Google a câştigat din ce în ce mai multă încredere în rândul vizitatorilor săi datorită rapidității şi eficienței găsirii informațiilor solicitate. Înscrierea unui site se face de la pagina: http://www.Google.com/addurl .

Ați observat faptul că rezultatele unei căutări făcute de Google sunt afişate pe mai multe pagini. Optzeci şi patru la sută dintre căutătorii de date nu trec niciodată de sfârşitul paginii a doua de rezultate oferite de motorul de căutare. Sunt multe de spus despre cum să procedați ca pagina dumneavoastră să fie cât mai bine cotată şi deci returnată de Google printre primele adrese. Gândiți-vă că David Viney a scris o întreagă carte cu titlul : „Cum să ajungi în top pe Google". Motorul de căutare Google dă fiecărei pagini web o notă de la 0 la 10 numită PageRank. PageRank-ul paginii dumneavoastra îl puteți identifica de la www.prchecker.info. Acestă notă oferită de Google măsoară prestigiul câştigat de site-ul dumneavoastră pe Internet. Un factor ce determină valoarea PageRank-ul unei pagini a site-ului dumneavoastră este numărul de legături oferite de alte site- 
uri către pagina dumneavoastră. $\mathrm{Cu}$ cât site-ul este mai recomandat de alte site-uri cu atât el e mai valoros. Similar: o lucrare ştiințifică este cu atât mai valoroasă cu cât este mai citată de alte lucrări. În concluzie, căutaţi să fiți recomandat de cât mai multe site-uri şi mai ales de site-uri cât mai valoroase.

Statistica vizitatorilor. Cel mai popular script pentru analiza statisticilor site-ului este scriptul Trafic. Majoritatea site-urilor româneşti sunt înscrise la acest serviciu.

Trafic oferă numeroase statistici importante. Cât de vizitat e un anumit site este evidențiat de numărul de vizitatori unici ce au accesat respectivul site. Dar ce este „,vizitatorul unic?”. O persoană care a accesat o pagină a site-ului de la un calculator efectuează o vizită, şi Trafic adaugă un nou vizitator unic în lista vizitatorilor. Un vizitator unic poate fi şi o rețea de calculatoare, o instituție. Concluzia este că nu putem şti numărul real de persoane care au vizitat site-ul nostru, deoarece nu putem şti câte persoane au accesat site-ul de pe un anumit calculator sau rețea de calculatoare.

\begin{tabular}{|c|c|c|c|c|}
\hline Dată & Vizitatori unici & Afişări & \multicolumn{2}{|c|}{ Evoluţie săp? } \\
\hline Luni, 28.02.2011 & 4 & 26 & $\sqrt{ }-$ & $69,23 \%$ \\
\hline Duminica, 27.02.2011 & 8 & 35 & 수 + & $14,29 \%$ \\
\hline Sambata, 26.02.2011 & 5 & 37 & & $0,00 \%$ \\
\hline Vineri, 25.02.2011 & 7 & 31 & $\checkmark-$ & $63,16 \%$ \\
\hline Joi, 24.02.2011 & 10 & 66 & & $0,00 \%$ \\
\hline Miercuri, 23.02.2011 & 7 & 41 & $\checkmark-$ & $12,50 \%$ \\
\hline Marti, 22.02.2011 & 8 & 39 & & $0,00 \%$ \\
\hline Luni, 21.02.2011 & 13 & 48 & $4+$ & $30,00 \%$ \\
\hline Duminica, 20.02 .2011 & 7 & 21 & 수 + & $75,00 \%$ \\
\hline
\end{tabular}

Trafic întocmeşte un clasament al site-urilor pe categorii în funcție de numărul de vizitatori.

Statistica Ultimele 100 de afişări prezintă: ultimele pagini afişate, durata vizualizării unei pagini, județul de unde s-a făcut vizualizarea, data vizualizării. 
Top pagini oferă un top al paginilor în funție de numărul de vizualizări. Astfel puteți cunoaşte care sunt cele mai vizitate şi cele mai puţin vizitate pagini ale site-ului. E important să ştim ce a captat mai mult atenția vizitatorilor. De exemplu, dacă observăm că secțiunea video e foarte accesată vom căuta să o îmbunătătim.

Dacă un vizitator ajunge pe site-ul dumneavoastră prin intermediul unei legături de pe un alt site aceasta se poate vizualiza la rubrica Ultimii 100 referreri. Astfel puteți afla cine vă recomandă şi cât de eficientă e acea recomandare.

Dacă un vizitator ajunge pe site-ul dumneavoastră prin intermediul unei căutări aceasta se poate vizualiza la rubrica Ultimele 100 de căutări.

Înscrierea unui site in trafic.ro costă 10 Euro pe an (fără TVA).

Testarea funcționalității. Testați funcționalitatea site-ului pe cât mai multe aplicații de vizualizare a paginilor web (browsere):

Microsoft Internet Explorer, ce va fi înlocuit recent de „Project Spartan” începând cu apariția pe piață a sistemului de operare Windows 10, dezvoltat de firma Microsoft, Mozilla Firefox,

Google Chrome, Apple Safari, Oopera .

O pagină poate avea un aspect frumos într-un anumit browser iar în altul poate avea un aspect neplăcut.

Din studiul prezentat, rezultă clar importanța utilizării mijloacelor multimedia în misiunea Bisericii. În cazul de faţă, site-ul parohial este un spațiu virtual de prezentare a vieții comunității chiar până în cele mai mici detalii.

\section{Bibliografie}

1. Arthur, Chris, The Globalization of Communications. Some religious implications, Geneva,WCC Publications, 1998. 
2. Dascălu, pr. Nicolae, Comunicare pentru comuniune, Iaşi, Ed. Trinitas, 2000.

3. Hristodoulos, Arhiepiscop al Atenei şi Primat al Greciei, Misiunea socială a Bisericii, trad. din lb. greacă de Arhi. Mihail Filimon, Pr. Petru Sidoreac, Protos. Dosoftei Scheul, Iaşi, Ed. Trinitas, 2000.

4. Mada, ierom. dr. Teofan, Evanghelia în versiunea Hollywood, Cluj Napoca, Ed. Vremi, 2010.

\section{Site-uri web:}

www.google.ro;

www.google.com;

www.rotld.ro;

www.prchecker.info;

www.domaintools.com;

www.trafic.ro;

www.parohiiortodoxe.ro;

www.episcopiaseverinului.ro;

www.sinaxar.ro;

www.sfgheorghe-severin.ro;

www.parohiaorsova.ro; 